\title{
Recent advances in the microbial synthesis of lactate-based copolymer
}

\author{
Pengye Guo ${ }^{1+}$, Yuanchan Luo ${ }^{1+}$, Ju Wu ${ }^{1}$ and Hui Wu ${ }^{1,2,3^{*}}$ (]
}

\begin{abstract}
Due to the increasing environmental pollution of un-degradable plastics and the consumption of non-renewable resources, more attention has been attracted by new bio-degradable/based polymers produced from renewable resources. Polylactic acid (PLA) is one of the most representative bio-based materials, with obvious advantages and disadvantages, and has a wide range of applications in industry, medicine, and research. By copolymerizing to make up for its deficiencies, the obtained copolymers have more excellent properties. The development of a one-step microbial metabolism production process of the lactate (LA)-based copolymers overcomes the inherent shortcomings in the traditional chemical synthesis process. The most common lactate-based copolymer is poly(lactate-co-3-hydroxybutyrate) $[\mathrm{P}(\mathrm{LA}-\mathrm{CO}-3 \mathrm{HB})]$, within which the difference of $\mathrm{LA}$ monomer fraction will cause the change in the material properties. It is necessary to regulate LA monomer fraction by appropriate methods. Based on synthetic biology and systems metabolic engineering, this review mainly focus on how did the different production strategies (such as enzyme engineering, fermentation engineering, etc.) of $\mathrm{P}(\mathrm{LA}-\mathrm{CO}-3 \mathrm{HB})$ optimize the chassis cells to efficiently produce it. In addition, the metabolic engineering strategies of some other lactate-based copolymers are also introduced in this article. These studies would facilitate to expand the application fields of the corresponding materials.
\end{abstract}

Keywords: Lactate-based copolymer, P(LA-co-3HB), Microbial synthesis, Production strategy

\section{Introduction}

Almost all traditional organic copolymers come from petrochemical industry, which will cause 'greenhouse effect', 'white pollution', and other environmental problems in the process of production, application, and management. With the increasing tension of resource development and people's continued attention to the environmental issues, most of the research concepts in recent years are in line with the characteristics of recycling and environmental protection. Bio-based polymers, which can be degraded by microorganisms and are made from natural materials, have attracted much attention in recent years (Taguchi

\footnotetext{
*Correspondence: hwu@ecust.edu.cn

${ }^{\dagger}$ Pengye Guo and Yuanchan Luo contributed equally to this work

${ }^{1}$ State Key Laboratory of Bioreactor Engineering, School

of Biotechnology, East China University of Science and Technology, 130

Meilong Road, Shanghai 200237, China

Full list of author information is available at the end of the article
}

et al. 2008; Matsumoto and Taguchi 2010; Park et al. 2012a; Yang et al. 2013; Choi et al. 2020b).

Nowadays, PLA is one of the most representative biobased polymers, its most notable features are biocompatibility and biodegradability (Pang et al. 2010; Shah et al. 2014). In addition to the above mentioned, PLA also has pros and cons, such as the advantages of high strength, high modulus, biocompostability, low toxicity, etc., as well as the disadvantages of hydrophobicity, low impact toughness, etc. Due to its complex biological and chemical production processes, PLA is relatively expensive compared with other commercial plastics (Lee et al. 2019; Singhvi et al. 2019). In order to make up for its shortcomings, copolymerization with other compositions is the most effective method. After copolymerization, the properties of PLA will be adjusted, such as degradation cycle, mechanical properties, hydrophilic properties, lipophilic properties, etc. At the same time, with the change of the composition and the proportion of the copolymers, PLA 
and its copolymers [belonging to polyhydroxyalkanoate (PHA), which is the general term for a class of bio-based polymers] will have more extensive applications, such as medical field (efficient nanocarriers for drug delivery applications, etc.) and other fields (Södergård and Stolt 2002; Makadia and Siegel 2011; Giammona and Craparo 2018; Singhvi et al. 2019; Su et al. 2020).

In 2008, Taguchi et al. (2008) firstly established a onestep microbial metabolic process for the synthesis of a representative lactate-based copolymer, $\mathrm{P}(\mathrm{LA}-\mathrm{co}-3 \mathrm{HB})$ (Fig. 1). The disadvantages of residues, which are generated in the process of chemical synthesis of the lactatebased copolymers, are effectively avoided by using the biosynthesis method. In addition, isolated microbial enzymes (such as lipase) also have been successfully used as catalysts for the production of the copolymers with diverse structures, various compositions and properties (Jiang and Zhang 2013).

In $\mathrm{P}(\mathrm{LA}-\mathrm{co}-3 \mathrm{HB})$, the molecular weight of it will decrease with LA monomer incorporating into the copolymer (Yamada et al. 2011). Thermodynamic analysis reveals that melting $\left(T_{\mathrm{m}}\right)$ and glass transition $\left(T_{\mathrm{g}}\right)$ temperatures of the copolymer vary with the change of the mole percentage of LA monomer fraction. The copolymer with the higher mole percentage of LA monomer fraction usually has a lower melting temperature $\left(T_{\mathrm{m}}\right)$ and a higher glass transition temperature $\left(T_{\mathrm{g}}\right)$ (Yamada et al. 2009, 2010, 2011; Ishii et al. 2017). However, Yamada et al. (2010) point out that the change of glass transition temperature $\left(T_{\mathrm{g}}\right)$ also needs to consider the molecular weight of the copolymer. In terms of the mechanical properties, Young's modulus of the copolymer is lower than that of the homopolymer, and it decreases with the increase of the mole percentage of LA monomer fraction. The elongation at break of the copolymer is higher than that of the homopolymer and can be maintained for a relatively long time (Yamada et al. 2011; Ishii et al.
2017). The crystallinity of cast film [mainly due to the crystallization of 3-hydroxybutyrate (3HB)] decreases with the increase of LA monomer fraction (Yamada et al. 2010; Ishii et al. 2017). When the mole percentage of LA monomer fraction of the copolymer is higher than $15 \%$, the transparency of the copolymer film increases significantly (Yamada et al. 2011).

It is meaningful to compare the material properties of $\mathrm{P}(\mathrm{LA}-\mathrm{co}-3 \mathrm{HB})$ with the homopolymers PLA and poly(3hydroxybutyrate) $[\mathrm{P}(3 \mathrm{HB})]$. PLA is a rigid, transparent, and compostable biodegradable material, $\mathrm{P}(3 \mathrm{HB})$ is rigid and opaque but has high biodegradability, while $\mathrm{P}$ (LAco-3HB) combines the advantages of PLA and $\mathrm{P}(3 \mathrm{HB})$ in terms of transparency and biodegradability (Taguchi and Matsumoto 2020). Whereas, compared with PLA, PHAs containing 3HB, 3-hydroxyvalerate (3HV), and 4-hydroxybutyrate (4HB) have a higher hazard (cytotoxicity) due to their relatively low acidity and bioactivity (Singh et al. 2019). In addition, the hydrophobicity of the lactate-based copolymers lead to its poor biocompatibility, which will limit its application in some fields (such as medical field). These existing shortcomings of the lactate-based copolymers indicate that further studies and developments are needed before their commercialization. While the commercialization of the lactate-based copolymers has not been reported, in recent years there are more and more researches focus on $\mathrm{P}(\mathrm{LA}-\mathrm{co}-3 \mathrm{HB})$. The properties [enantiomeric purity; sequential structure and molecular weight; thermal and mechanical properties (Nduko and Taguchi 2019)] of P(LA-co-3HB) are affected by the mole percentage of incorporated monomers, and different properties will affect its application in different fields. Therefore, it is very important to regulate the mole percentage of the monomer composition in the copolymers, especially to increase the mole percentage of LA monomer fractions in the copolymers. However, researchers will face the problems of the poor specificity

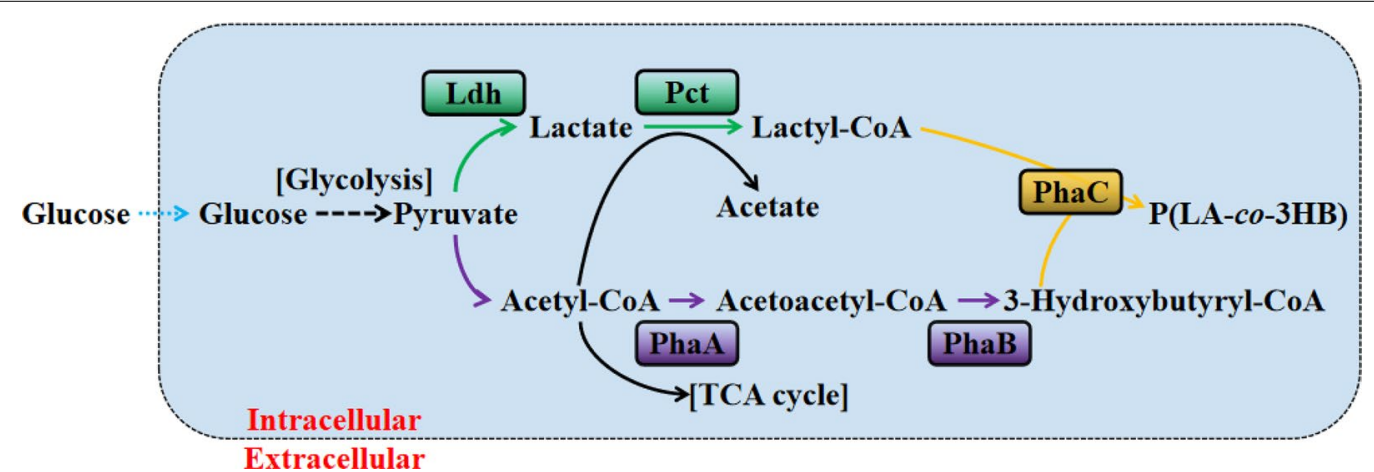

Fig. 1 Synthetic pathway of $P(L A-c o-3 H B)$ in recombinant Escherichia coli. Letters in boxes indicate enzymes. Ldh lactate dehydrogenase, Pct propionyl-CoA transferase, PhaA ß-ketothiolase, PhaB NADPH-dependent acetoacetyl-CoA reductase, PhaC PHA synthase 
of precursor supply enzymes and PHA synthases, as well as the inappropriate chassis cells, etc. So it is necessary to adjust microbial metabolic pathways through genetic engineering, fermentation engineering, etc. (Park et al. 2012a; Matsumoto and Taguchi 2013a, b).

Although the main contents of this article are the different production strategies of biosynthetic P(LA-co$3 \mathrm{HB})$, the representative lactate-based copolymer, other microbial synthesis strategies of PHA containing LA are also introduced here (Table 1).

\section{Different engineered strategies of $E$. coli for $\mathrm{P}(\mathrm{LA}-\mathrm{CO}-3 \mathrm{HB})$ biosynthesis \\ Enzyme engineering}

The wild-type $E$. coli cannot provide D-LA-CoA, which is required for copolymer synthesis, so CoA transferase is needed to produce it. Propionate-CoA transferase of Clostridium propionicum ( Pct $_{C p}$ ) is one of the most representative CoA transferases. In addition, Pct of $\mathrm{Meg}$ asphaera elsdenii has also been used, which contribute to the heterologous expression in E. coli (Taguchi et al. 2008). Different precursors containing CoA require polymerization of $\mathrm{PhaC}$, and the $\mathrm{PhaC}$ that can polymerize LA into the copolymers effectively is called LA-CoA polymerizing enzyme (LPE); the discovery of LPE is a decisive breakthrough in the biosynthesis of the lactatebased copolymers (Taguchi et al. 2008; Matsumoto and Taguchi 2013b). To adjust the monomer composition of the copolymers, researchers are committed to discovering new enzymes or improving the activity and the substrate specificity of existing enzymes by random mutagenesis, screening, or structure prediction based on homologous sequences of identified enzymes (Choi et al. 2020b).

LPE is created by introducing double mutations, S325T and Q481K, into PHA synthase 1 ( $\left.\mathrm{PhaC}_{P s 6-19}\right)$ of Pseudomonas sp. 61-3 (Taguchi et al. 2008; Tajima et al. 2009). To find the same effect, the same mutations are introduced into Pseudomonas sp. MBEL 6-19 at the corresponding sites of PHA synthase $1\left(\mathrm{PhaC}_{P s 6-19}\right)$. The mutant enzyme cannot polymerize LA-CoA into the copolymers effectively. Its activity can be improved by gene mutations of its four sites (E130, S325, S477, and Q481), which are previously addressed through evolutionary engineering studies performed by Taguchi's group (Taguchi and Doi 2004; Shozui et al. 2009) (Yang et al. 2010). Further engineered type II Pseudomonas PHA synthases 1 (PhaC1s) are obtained from Pseudomonas chlororaphis, Pseudomonas sp. 61-3, Pseudomonas putida KT2440, Pseudomonas resinovorans, and Pseudomonas aeruginosa PAO1 by mutagenesis of four sites (E130, S325, S477, and Q481) (Yang et al. 2011). Base on the $\mathrm{PhaC1}_{P S 6-19}$ (Taguchi et al. 2008), another mutant, F392, is obtained. Engineered E. coli BW25113 (with mutated PHA synthase, F392S) along with the pyruvate formate lyase activating enzyme gene ( $p f l A)$ deletion can synthesize $62 \mathrm{wt} \% \mathrm{P}(45 \mathrm{~mol} \% \mathrm{LA}-c o-3 \mathrm{HB})$ in a medium containing $20 \mathrm{~g} / \mathrm{L}$ glucose with the highest LA monomer fraction (Yamada et al. 2010). Ren et al. (2017) examine the mutation effects of PhaC1 (E130D, S325T, F392S, S477G, and Q481K) and PhaC2 (S326T, S478G, and Q482K) of Pseudomonas stutzeri. Lu et al. (2019) examine the mutation effects of PhaCm (E130D, S325T, and $\mathrm{Q} 481 \mathrm{~K}$ ) of Pseudomonas fluorescens. In addition, it should be noted that LPE has a strict substrate specificity toward D-LA-CoA, which is obtained from enantiomer analysis of $\mathrm{P}(\mathrm{LA}-c o-3 \mathrm{HB})$ synthesized in vivo and analysis of LPE in vitro, the synthesized copolymers by LPE are almost entirely composed of D-LA (Tajima et al. 2009; Yamada et al. 2009; Matsumoto and Taguchi 2013b).

Type I PHA synthase of Cupriavidus necator $\left(\mathrm{PhaC}_{R e}\right)$ exhibits activity toward 2-hydroxybutyryl-CoA (2HB$\mathrm{CoA}$ ) in vitro (Han et al. 2011). Similar to position 481 in type II PHA synthase ( $\left.\mathrm{PhaC} 1_{P s 6-19}\right)$ (Taguchi et al. 2008), $\mathrm{PhaC}_{R e}$ is mutated at position 510. Partially engineered E. coli LS5218 (A510X) can synthesize the copolymers in a medium with $5 \mathrm{~g} / \mathrm{L}(R)$-LA and $3 \mathrm{~g} / \mathrm{L}$ sodium dodecanoate, indicating that 510 residue plays a key role in LA polymerization (Ochi et al. 2013).

Pct $_{C p}$ cannot convert LA into LA-CoA effectively, and it also exert the inhibitory effects on cell growth (Yang et al. 2010). While when some sites of $\operatorname{Pct}_{C p}$ are mutated, its activity can be promoted and the inhibition of cell growth can be alleviated. Two beneficial Pct ${ }_{C p}$ mutants have been constructed to achieve these two goals. One mutant is Pct532 $C p$, within which with amino acid mutation of A243T and A1200G (silent nucleotide mutation). Another mutant is Pct540 $C p$ with amino acid mutation of V193A and four silent nucleotide mutations of T78C, T669C, A1125G, as well as T1158C (Yang et al. 2010). Engineered E. coli XL1-Blue with the expression of the phaC1437 gene of Pseudomonas sp. MBEL 6-19 and the CB3819 gene (or the CB4543 gene) of Clostridium beijerinckii can synthesize $\mathrm{P}(3 \mathrm{HB})$ within a medium containing $20 \mathrm{~g} / \mathrm{L}$ glucose and $2 \mathrm{~g} / \mathrm{L}$ sodium $3 \mathrm{HB}$. Engineered E. coli XL1-Blue with the expression of the pct gene of Clostridium perfringens can synthesize $10.6 \mathrm{wt} \% \mathrm{P}(13.6 \mathrm{~mol} \%$ LA-co-3HB) in the same culture media too (Kim et al. 2016). Four butyryl-CoA transferases (Bct) of Roseburia sp., Eubacterium hallii, Faecalibacterium prausnitzii, and Anaerostipes caccae can polymerize LA, $2 \mathrm{HB}$, and $3 \mathrm{HB}$ with different activities (David et al. 2017).

Moreover, cinnamoyl-CoA:phenyllactate CoA-transferase (FldA) of Clostridium sporogenes can transfer CoA from cinnamoyl-CoA to phenyllactate and 4-hydroxyphenyllactate; isocaprenoyl-CoA:2-hydroxyisocaproate 


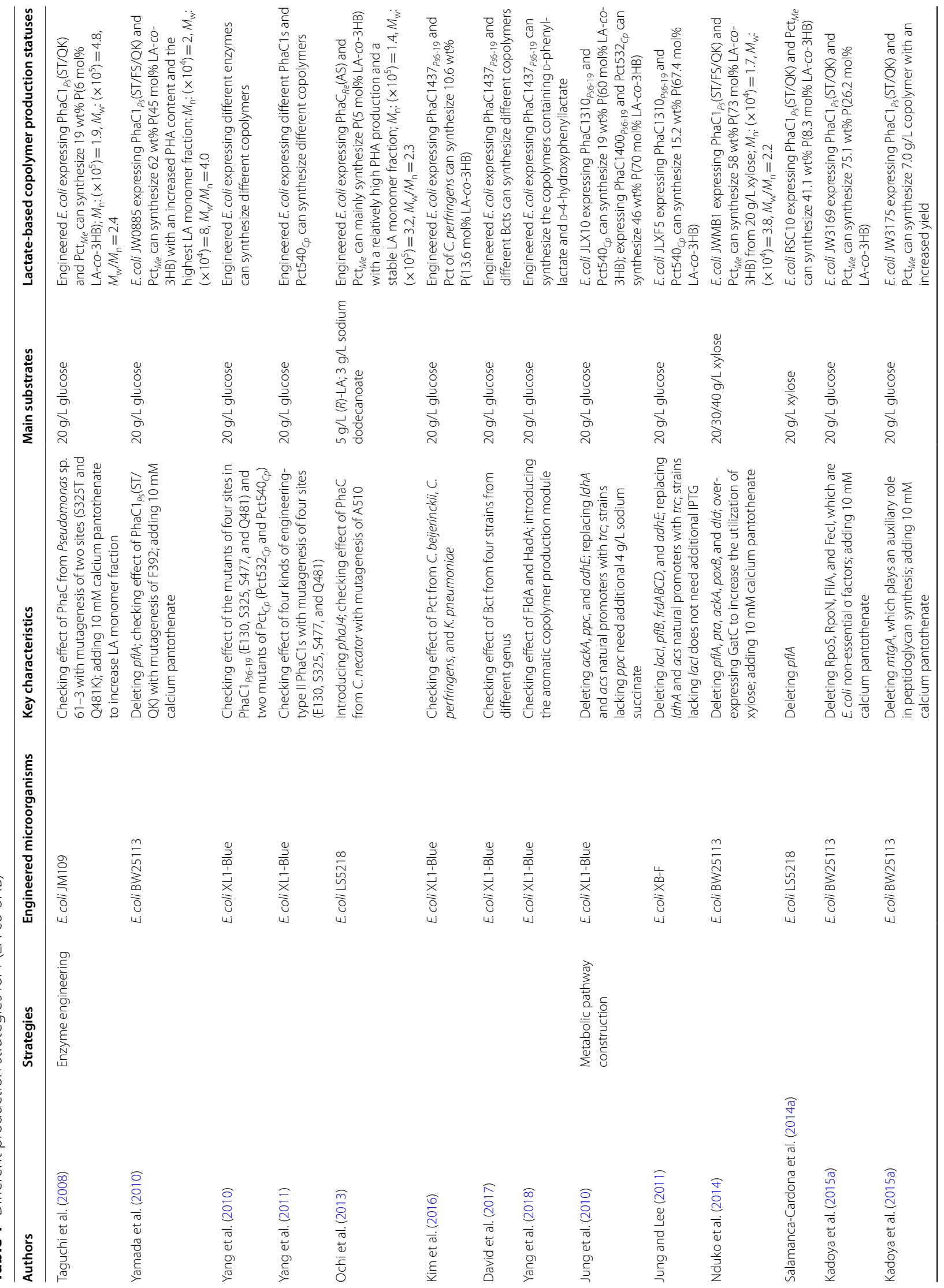



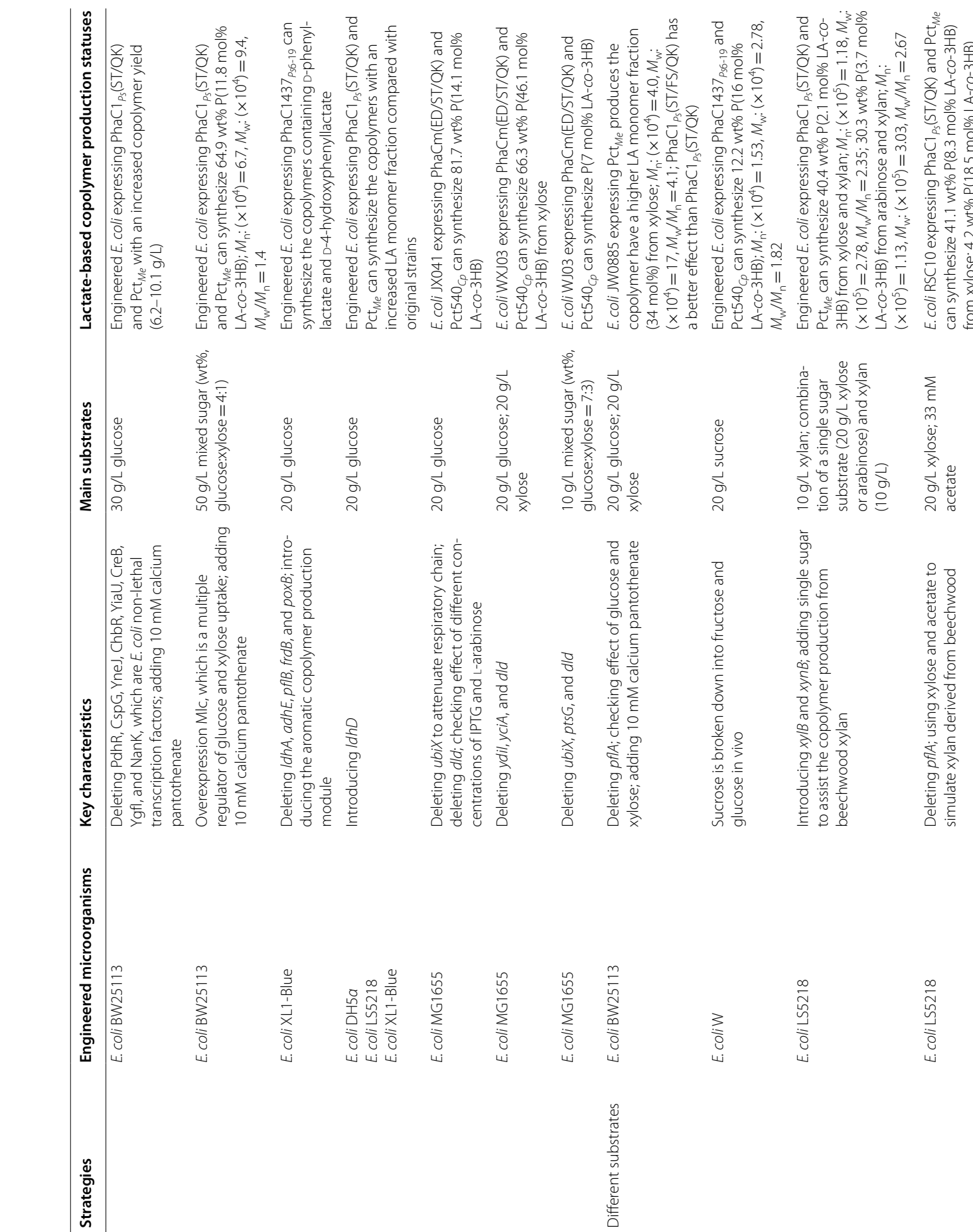

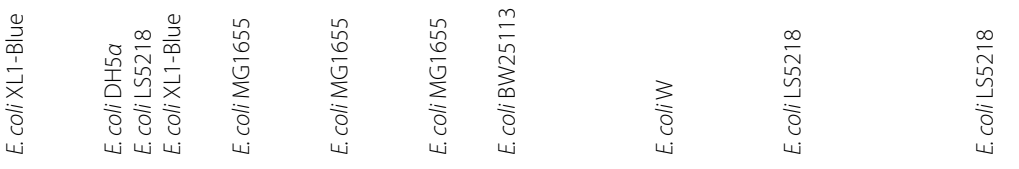

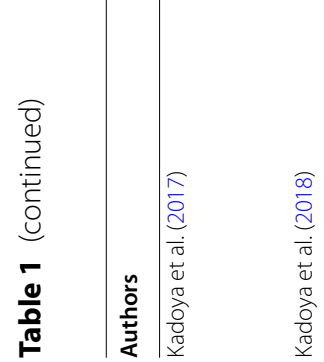

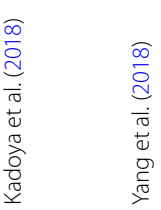
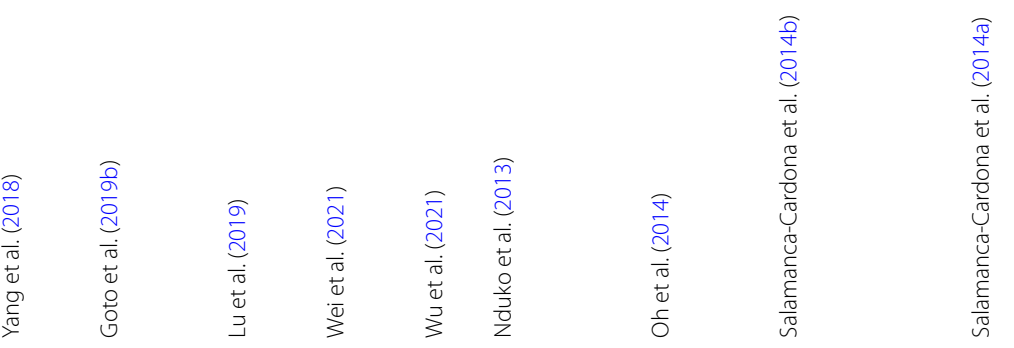


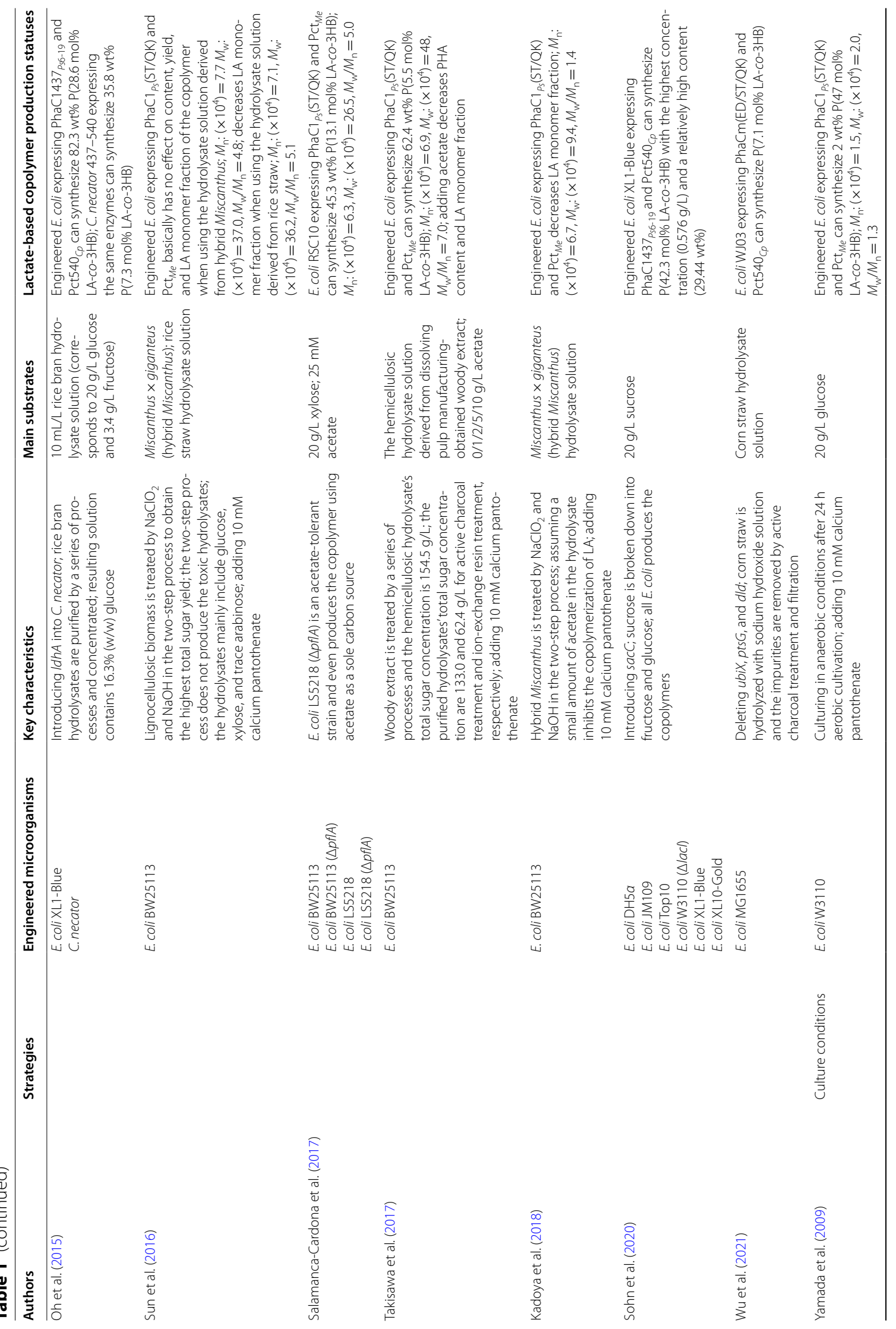




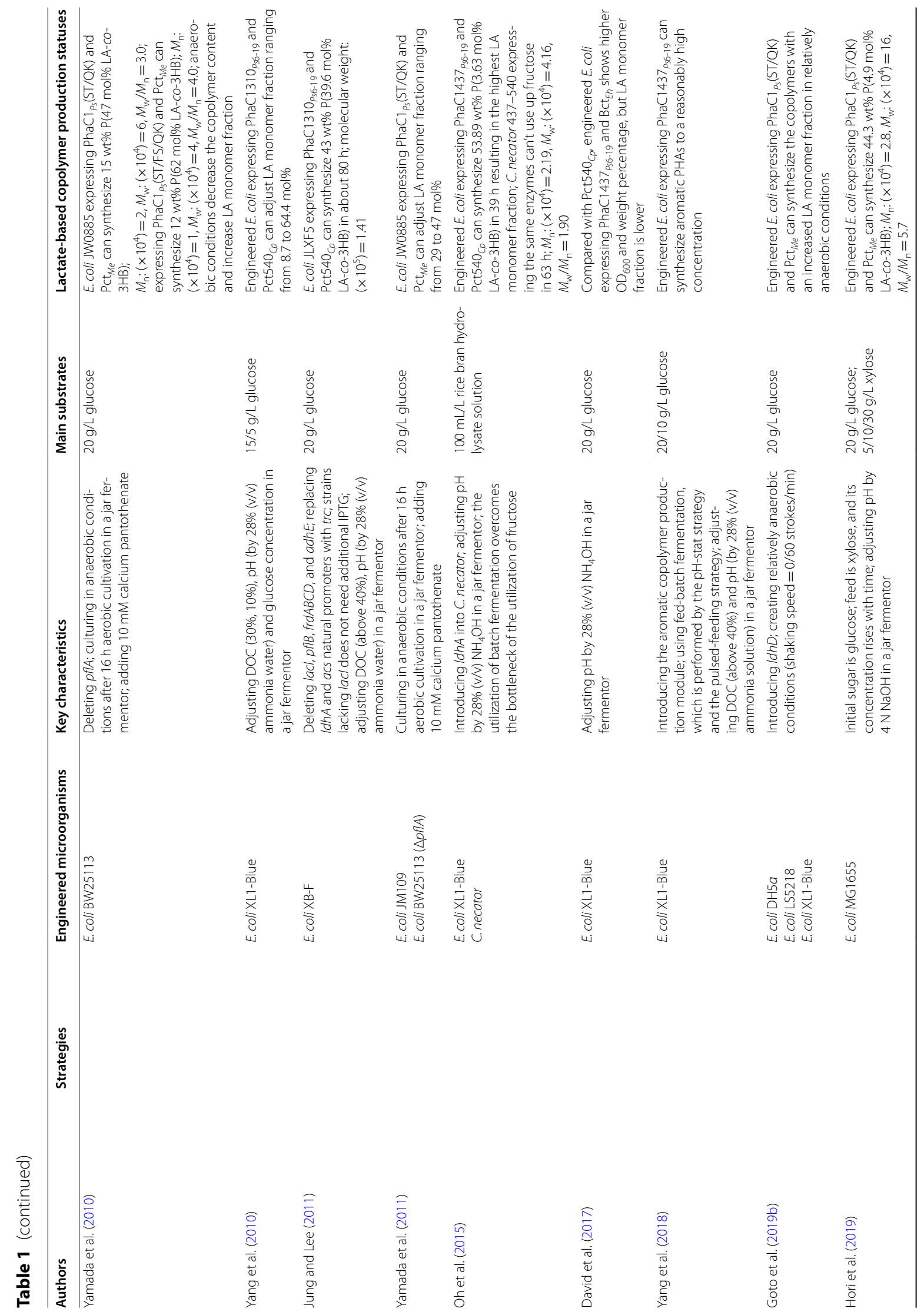


CoA-transferase (HadA) of Clostridium difficile which can use acetyl-CoA as a CoA donor is further identified, and have been revealed that it has a wider substrate spectrum than FldA (Yang et al. 2018).

\section{Metabolic pathway engineering}

Lactyl-CoA and acetyl-CoA are two precursors of P(LA$c o-3 \mathrm{HB})$, both of them are derived from pyruvate. These indicate that regulation of metabolic flux of pyruvate is an effective method to adjust LA monomer fraction in the copolymers. The overexpression of the key pathway genes or blocking competitive pathways are both effective metabolic engineering strategies to achieve this gold. Except for these two strategies, there are still some other methods that can adjust LA monomer fraction in the copolymers.

The deletion of the acetate kinase gene $(a c k A)$ and the phosphoenolpyruvate carboxylase gene $(p p c)$, as well as the replacement of the native promoter of the D-lactate dehydrogenase gene $(l d h A)$ with the $\operatorname{trc}$ promoter, can regulate the metabolic flux by rational engineering. In addition, the deletion of the acetaldehyde/alcohol dehydrogenase gene $(a d h E)$ and the replacement of the native promoter of the acetyl-CoA synthetase gene (acs) with the $\operatorname{trc}$ promoter by in silico gene knockout simulation as well as flux response analysis can further regulate the metabolic flux. Engineered E. coli XL1-Blue increased the copolymer content and LA monomer fraction up to ca. 3.7-fold (in case of expressing PhaC1310 ${ }_{P s 6-19}$, Pct540 ${ }_{C p}$, and $\mathrm{PhaAB}_{C n}$ ) and 2.6-fold (in case of expressing PhaC1400 $P_{s 6-19}, \mathrm{Pct}_{532_{C p}}$, and $\mathrm{PhaAB}_{C n}$ ), respectively (Jung et al. 2010). With the deletion of the pyruvate formate lyase gene $(p f l B)$, the fumarate reductase gene (frdABCD), and the adhE gene, engineered $E$. coli XB-F can synthesize $15.2 \mathrm{wt} \% \mathrm{P}(67.4 \mathrm{~mol} \% \mathrm{LA}-c o-3 \mathrm{HB})$ in a medium containing $20 \mathrm{~g} / \mathrm{L}$ glucose along with the trc promoter replacement of the ldhA and acs genes (Jung and Lee 2011). Partial deletion of other target genes, such as the $p f l A$ gene, the phosphate acetyltransferase gene $(p t a)$, the pyruvate oxidase gene $(p o x B)$, the $\mathrm{NAD}^{+}$-independent lactate dehydrogenase gene $(d l d)$, and the ack $A$ gene, are also conducive to improve the copolymers. With the deletion of the pflA and dld genes, engineered $E$. coli BW25113 can synthesize $58 \mathrm{wt} \%$ $\mathrm{P}(73 \mathrm{~mol} \% \mathrm{LA}-c o-3 \mathrm{HB})$ in a medium containing $20 \mathrm{~g} / \mathrm{L}$ xylose. In addition, the overexpression of non-ATP consuming galactitol permease (GatC) to promote the absorption of xylose can increase the copolymer yield and LA monomer fraction of some mutants (Nduko et al. 2014). PflB is regulated by PflA, then the deletion of the $\mathrm{pflA}$ gene can increase the flux of pyruvate into LA and acetyl-CoA. Engineered E. coli LS5218 can synthesize $45.1 \mathrm{wt} \% \mathrm{P}(0.9 \mathrm{~mol} \% \mathrm{LA}-c o-3 \mathrm{HB})$ in a medium with 
$20 \mathrm{~g} / \mathrm{L}$ glucose and $41.1 \mathrm{wt} \% \mathrm{P}(8.3 \mathrm{~mol} \% \mathrm{LA}-\mathrm{co}-3 \mathrm{HB})$ in a medium with $20 \mathrm{~g} / \mathrm{L}$ xylose, respectively. However, when compared with the wild-type strain, the increase of LA monomer fraction could be offset for the significantly lower total cell biomass (Salamanca-Cardona et al. 2014a). Engineered E. coli BW25113 along with the deletion of the monofunctional peptidoglycan transglycosylase gene ( $m t g A)$ can enhance the copolymer production. Simultaneously, with the deletion of $m \operatorname{tg} A$, the widths of the mutant cells become wilder than that of the wildtype cells (Kadoya et al. 2015a). The introduction of the D-LDH gene (ldhD) of Lactobacillus acetotolerans HT into different $E$. coli allows the improvement of LA monomer fraction (Goto et al. 2019b). Moreover, one-step production of the copolymers containing phenyllactate and 4-hydroxyphenyllactate from glucose by engineered E. coli XL1-Blue is designed. The globally metabolic engineering strategy of this one-step production of the copolymers includes the deletions of the $l d h A, a d h E, p f l B, f r d B$, and poxB genes (Yang et al. 2018).

The cultivation of $E$. coli with mixed sugar will cause carbon catabolite repression, which can be derepressed by the overexpression of Mlc, a multiple regulator of glucose and xylose uptake. Engineered E. coli BW25113 can synthesize $64.9 \mathrm{wt} \% \mathrm{P}(11.8 \mathrm{~mol} \% \mathrm{LA}-\mathrm{co}$ $3 \mathrm{HB}$ ) in a medium with $50 \mathrm{~g} / \mathrm{L}$ mixed sugar (wt\%, glucose:xylose $=4: 1$ ). In the same experiment, an increase in cell length is also observed, which is helpful for the accumulation of the copolymer (Kadoya et al. 2018).

Aim to change the copolymer production and the monomer composition, we can also disrupt $\sigma$ factors, which globally govern the transcription of the corresponding genes. E. coli possesses four non-essential $\sigma$ factors, RpoS, RpoN, FliA, and FecI. Engineered E. coli BW25113 along with the rpoN gene deletion can synthesize $75.1 \mathrm{wt} \% \mathrm{P}(26.2 \mathrm{~mol} \% \mathrm{LA}-\mathrm{co}-3 \mathrm{HB})$ in a medium containing $20 \mathrm{~g} / \mathrm{L}$ glucose, which is superior to that of the wild-type strain (Kadoya et al. 2015b). Furthermore, all of the deletions of non-lethal transcription factors of E. coli are screened by Keio Collection test. Among 252 mutants, eight of them, $\Delta p d h R, \Delta c s p G, \Delta y n e J, \Delta c h b R$, $\Delta y i a U, \Delta c r e B, \Delta y g f I$, and $\Delta n a n K$, increase the copolymer yield $(6.2-10.1 \mathrm{~g} / \mathrm{L})$ when compared to E. coli BW25113 $(5.1 \mathrm{~g} / \mathrm{L})$ in a medium containing $30 \mathrm{~g} / \mathrm{L}$ glucose with an insignificant change in cell density (Kadoya et al. 2017).

Attenuating respiratory chain increases the accumulation of LA in E. coli under aerobic conditions. The deletion of the flavin prenyltransferase gene $(u b i X)$ can implement this strategy by attenuating the synthesis of coenzyme Q8, a key ingredient involved in respiratory chain in E. coli. Engineered E. coli MG1655 along with the dld gene deletion can synthesize $81.7 \mathrm{wt} \%$ $\mathrm{P}(14.1 \mathrm{~mol} \% \mathrm{LA}-\mathrm{co}-3 \mathrm{HB})$ in a medium containing $20 \mathrm{~g} / \mathrm{L}$ glucose (Lu et al. 2019). On this basis, the Pct540 ${ }_{C p}$ promoter is replaced with the $l d h A$ promoter, and the glucose-specific PTS enzyme IIBC component gene ( $p t s G$ ) is knocked out to weaken carbon catabolite repression. Engineered E. coli MG1655 can synthesize $\mathrm{P}(7 \mathrm{~mol} \%$ LA-co-3HB) in a medium containing $10 \mathrm{~g} / \mathrm{L}$ mixed sugar ( $w t \%$, glucose:xylose $=7: 3$ ), but LA monomer fraction is decreased compared with strain without the $p t s G$ gene deletion (Wu et al. 2021). Another strategy is proposed by the same research group too, which is aimed to delete the thioesterase genes ( $y d i I$ and $y c i A$ ) to prevent the degradation of intracellular LA-CoA. Engineered E. coli MG1655 along with the $d l d$ gene deletion can synthesize $66.3 \mathrm{wt} \% \mathrm{P}(46.1 \mathrm{~mol} \% \mathrm{LA}-\mathrm{co}-3 \mathrm{HB})$ in a medium containing $20 \mathrm{~g} / \mathrm{L}$ xylose. It should be pointed out that the lack of thioesterase plays a major regulatory role (Wei et al. 2021). The presence of LA-CoA degrading enzymes (LDEs) (such as thioesterase) may lead to extremely low intracellular LA-CoA content in E. coli, which accounts for the efficient copolymer production (Matsumoto et al. 2018). The deletion of similar enzymes may increase LA monomer fraction in the copolymers while preventing the extension of the copolymer chain (Matsumoto et al. 2018). Potential LDEs [such as possible short-chain fatty acyl-CoA degrading enzymes (Clomburg et al. 2012)] are promising as elements for regulating the copolymer composition.

\section{Different culture conditions of $E$. coli for $\mathrm{P}(\mathrm{LA}-\mathrm{CO}-3 \mathrm{HB})$ biosynthesis}

Introducing LPE and monomer synthesis enzymes into the pflA gene deleted E. coli BW25113, the copolymer in the mutant growing on $20 \mathrm{~g} / \mathrm{L}$ xylose has a higher LA monomer fraction (34 mol\%) than that growing on $20 \mathrm{~g} / \mathrm{L}$ glucose (LA monomer fraction is $26 \mathrm{~mol} \%$ ). The utilization of evolved LPE (ST/FS/QK) can further enhance this advantage (Nduko et al. 2013). Introduction of the endoxylanase gene $(x y l B)$ of Streptomyces coelicolor and the $\beta$-xylosidase gene $(x y n B)$ of Bacillus subtilis into $E$. coli LS5218 allows converting xylan into PHA in vivo. Furthermore, when xylose or arabinose is added to the media at the same time, the production yields of PHA in engineered E. coli can increase up to 18-fold (SalamancaCardona et al. 2014b). Sucrose is undoubtedly one of the most abundant and the least expensive carbon sources. Engineered E. coli W can break down $20 \mathrm{~g} / \mathrm{L}$ sucrose into fructose and glucose, and further to synthesize $12.2 \mathrm{wt} \% \mathrm{P}(16 \mathrm{~mol} \% \mathrm{LA}-\mathrm{co}-3 \mathrm{HB})$ in vivo (Oh et al. 2014). To establish an efficient sucrose utilization pathway, the $\beta$-fructofuranosidase gene (sacC) of Mannheimia succiniciproducens MBEL55E is introduced into different genetically modified E. coli strains. Among the tested recombinant $E$. coli strains, engineered $E$. coli XL1-Blue 
synthesize the $\mathrm{P}(42.3 \mathrm{~mol} \% \mathrm{LA}-\mathrm{co}-3 \mathrm{HB})$ with the highest concentration of $0.576 \mathrm{~g} / \mathrm{L}$ and a relatively high content of $29.44 \mathrm{wt} \%$ in a medium containing $20 \mathrm{~g} / \mathrm{L}$ sucrose (Sohn et al. 2020).

Using traditional carbon sources such as glucose to produce the copolymers is a simple and effective method, but the copolymers' increase in the production and the expansion of the use scope are inhibited by high raw material costs, so it is necessary to focus on the development of the inexpensive materials. By-products from different processing industries have great potentials, such as the residues of the biodiesel industry (Plácido and Capareda 2016), chitin and chitosan extracted from the marine waste resources (Yadav et al. 2019), the wastes of milk processing and reducing such as cheese whey (Zikmanis et al. 2020), lignocellulosic biomass and other green wastes (Langsdorf et al. 2021), as well as pulp and paper mill wastes (Haile et al. 2021). Some non-traditional carbon sources are not only beneficial to the copolymer production to a certain extent, but also can reduce the risk of the environmental pollution.

Rice bran is a by-product of the rice manufacturing process, and possesses certain potential as a feedstock for bio-based polymers. A rice bran treatment process has been developed to produce $43.7 \mathrm{~kg}$ hydrolysate solution containing $24.41 \mathrm{~g} / \mathrm{L}$ glucose and a small amount of fructose from $5 \mathrm{~kg}$ rice bran (Oh et al. 2015). With the expression of LPE and monomer supplying enzymes, engineered $E$. coli XL1-Blue can synthesize $82.3 \mathrm{wt} \%$ $\mathrm{P}(28.6 \mathrm{~mol} \% \mathrm{LA}-$ co-3HB) in $10 \mathrm{~mL} / \mathrm{L}$ hydrolysate solution; C. necator 437-540 can synthesize $35.8 \mathrm{wt} \%$ $\mathrm{P}(7.3 \mathrm{~mol} \% \mathrm{LA}-\mathrm{co}-3 \mathrm{HB})$ in the same condition (Oh et al. 2015).

$\mathrm{P}(\mathrm{LA}-\mathrm{co}-3 \mathrm{HB})$ can be produced from glucose or xylose, which demonstrates the feasibility of using lignocellulosic-like biomass as a carbon source to produce P(LAco-3HB). Wu et al. (2021) use corn stover hydrolysate to synthesize $\mathrm{P}(7.1 \mathrm{~mol} \% \mathrm{LA}-\mathrm{co}-3 \mathrm{HB})$ successfully, although cell growth is slightly inhibited. Compared with pure sugars, Sun et al. (2016) find that the hydrolysate solution derived from Miscanthus $\times$ giganteus (hybrid Miscanthus) does not affect content, yield, and LA monomer fraction of the copolymer, while the hydrolysate solution derived from rice straw decrease LA monomer fraction. However, some other researchers find that using the hydrolysate solution derived from hybrid Miscanthus will lead to a decrease in LA monomer fraction of the copolymer, which is suspected to be the effect of a small amount of acetate in the biomass sugar solution (Kadoya et al. 2018).

The hemicellulosic hydrolysate solution derived from dissolving pulp manufacturing-obtained woody extract is mainly composed of xylose and galactose, but a small amount of acetate contained in the hydrolysate solution will inhibit copolymer synthesis. After treating with active charcoal and ion-exchange columns to remove acetate, engineered E. coli BW25113 can synthesize $62.4 \mathrm{wt} \% \mathrm{P}(5.5 \mathrm{~mol} \% \mathrm{LA}-\mathrm{co}-3 \mathrm{HB})$ in a medium containing the hydrolysate solution (Takisawa et al. 2017). The above conclusions all clarified the adverse effect of acetate on the copolymer production.

Although acetate inhibits copolymer synthesis, some acetate-tolerant strains are still discovered. The process of using engineered $E$. coli LS5218 along with the pflA gene deletion to produce the copolymers suggests that acetate played an important role in controlling LA monomer incorporation into the copolymers (SalamancaCardona et al. 2014a). Compared to using $20 \mathrm{~g} / \mathrm{L}$ xylose alone, the overall yields of engineered E. coli LS5218 along with the $p f l A$ gene deletion increase by more than twofold with the presence of $25 \mathrm{mM}$ acetate. In addition, when $25 \mathrm{mM}$ acetate is used as the sole carbon source, the copolymer still can be synthesize by strain (Salamanca-Cardona et al. 2017).

High reducing power brought by anaerobic cultivation is beneficial to an increase in the flux toward LA-CoA. After a $24 \mathrm{~h}$ aerobic cultivation, engineered $E$. coli W3110 can synthesize $2 \mathrm{wt} \% \mathrm{P}(47 \mathrm{~mol} \% \mathrm{LA}-\mathrm{co}-3 \mathrm{HB})$ when it is transferred into anaerobic conditions and is further cultured for another $24 \mathrm{~h}$ in a medium with $20 \mathrm{~g} / \mathrm{L}$ glucose (Yamada et al. 2009). $12 \mathrm{wt} \% \mathrm{P}(62 \mathrm{~mol} \% \mathrm{LA}-$ co-3HB) can be synthesized by combining anaerobic cultivation with engineered E. coli BW25113 along with the pflA gene deletion as well as carrying LPE of F392S mutant (Yamada et al. 2010). LA monomer fraction of the copolymers produced by engineered $E$. coli BW25113 along with the pflA gene deletion can be adjusted between the range from 29 to $47 \mathrm{~mol} \%$ by the fine-regulation of the culture conditions in anaerobic cultivation with a medium containing $20 \mathrm{~g} / \mathrm{L}$ glucose within a fermentation tank (Yamada et al. 2011). In addition, relatively anaerobic conditions (shaking speed $=0 / 60$ strokes $/ \mathrm{min}$ ) can also increase LA monomer fraction in the copolymers (Goto et al. 2019b).

Fed-batch cultivation is an important technology to achieve high cell density and high volumetric productivity in a fermentation tank. By adjusting dissolved oxygen concentration (DOC) and glucose concentration (upon $\mathrm{pH}$-stat feeding), LA monomer fraction can be adjusted between the range from 8.7 to $64.4 \mathrm{~mol} \%$ by engineered E. coli XL1-Blue (Yang et al. 2010). Jung and Lee (2011) increase the weight percentage of $\mathrm{P}(\mathrm{LA}-\mathrm{co}-3 \mathrm{HB})$ by fedbatch cultivation, but LA monomer fraction is decreased. The utilization of the $\mathrm{pH}$-stat strategy or the pulsedfeeding strategy can produce aromatic PHAs to a reasonably high concentration (Yang et al. 2018). In addition, 
$20 \mathrm{~g} / \mathrm{L}$ initial glucose concentration $(0-24 \mathrm{~h})$ is used for cell growth, and xylose (24-81.6 h) is used for the copolymer production, the feeding rate of the sugar solution is increased in a stepwise manner. Under this condition, engineered E. coli MG1655 can synthesize 44.3 wt\% $\mathrm{P}(4.9 \mathrm{~mol} \% \mathrm{LA}-\mathrm{co}-3 \mathrm{HB})$ and the copolymer production increases significantly (Hori et al. 2019). Moreover, batch fermentation technology is used to overcome the bottleneck of the utilization of fructose, which is one of the components of rice bran (Oh et al. 2015)/sucrose (Sohn et al. 2020) hydrolysates. Compared with Pct540 ${ }_{C p}$, engineered E. coli XL1-Blue expressing PhaC1437 $P_{s 6-19}$ and $\mathrm{Bct}_{E h}$ in batch fermentation shows higher $\mathrm{OD}_{600}$ and weight percentage, but LA monomer fraction is lower (David et al. 2017).

\section{Introduction of other monomers into lactate-based PHA}

Engineered $E$. coli can synthesize LA-CoA by introducing Pct, synthesize $3 \mathrm{HB}-\mathrm{CoA}$ by introducing $\mathrm{PhaAB}$, and synthesize the copolymers by introducing LPE. Similarly, other monomers can be introduced into the copolymers by transforming the corresponding CoA metabolic pathway into $E$. coli. Alternatively, monomers can be added to the substrate directly and then use the one-pot method to produce the copolymers (Matsumoto et al. 2013). Different monomer copolymerization strategies are summarized in Fig. 2.

\section{Introduction of 2HB biosynthesis pathway}

The introduction of the citramalate synthase gene (cimA3.7) of Methanococcus jannaschii, the 3-isopropylmalate dehydrogenase gene (leuB) and the isopropyl malate (IPM) isomerase gene (leuCD) of E. coli W3110, as well as the $2 \mathrm{HB}$ dehydrogenase gene (panE) of Lactococcus lactis subsp. lactis Il1403 into E. coli XL1-Blue allows converting glucose into $2 \mathrm{HB}$ in vivo (Park et al. 2012b, 2013a; Chae et al. 2016; David et al. 2017). By introducing the propionyl-CoA synthetase gene ( $p r p E)$ of $C$. necator and using the inherent pyruvate dehydrogenase complex (PDHc), E. coli XL1-Blue allows converting propionate into $2 \mathrm{HB}$ with the help of the panE gene in vivo. In addition, the deletion of the 2-methylcitrate synthase gene $(\operatorname{prp} C)$ can increase $2 \mathrm{HB}$ monomer fraction in the copolymers, while it will decrease the copolymer content (Park et al. 2013a). Moreover, E. coli can endogenously produce $\mathrm{L}$-threonine, which can be transformed into $2 \mathrm{HB}$ with the help of the panE gene (Yang et al. 2016) or into 2HB-CoA with the help of the $l d h A$ and hadA genes of C. difficile 630 (Mizuno et al. 2018; Sudo et al. 2020). The deletion of the L-threonine dehydratase gene $(i l v A)$, will lead to the remove $2 \mathrm{HB}$ from the copolymers. However, since $i l v A$ is the crucial gene for amino acid biosynthesis, the deletion of it in $E$. coli will result in the growth retardation and the decrease of the copolymer content. Considering the activity of L-threonine dehydratase can be inhibited allosterically by L-isoleucine, the same effect can be achieved by the strategy of adding L-isoleucine into the medium (Choi et al. 2016, 2017; Yang et al. 2016; Choi et al. 2020a). In order to increase $2 \mathrm{HB}$ monomer fraction, L-threonine can be added to the medium (Sudo et al. 2020). Furthermore, $\mathrm{L}$-valine can also achieve the same effect, because the activity of acetohydroxy acid synthase is negatively regulated by L-valine (Yang et al. 2016; Sudo et al. 2020). In another explanation, L-valine is pointed out that allosterically activates $\mathrm{L}$-threonine deaminase and catalyzes L-threonine to form 2-ketobutyrate (Sudo et al. 2020). Sudo et al. (2020) indicate that L-valine inhibits bacteria growth and leads to a decrease in the copolymer production, but this phenomenon is not discussed by Yang et al. (2016).

\section{Introduction of 4HB biosynthesis pathway}

The introduction of the succinate semialdehyde dehydrogenase gene $(s u c D)$, the $4 \mathrm{HB}$ dehydrogenase gene $(4 h b D)$, and the CoA transferase gene (orfZ) of Clostridium kluyveri DSM555 into E. coli JM109 allows converting glucose into $4 \mathrm{HB}-\mathrm{CoA}$ in vivo (Li et al. 2017). With the introduction of the $s u c D$ and $4 h b D$ genes into $E$. coli XL1-Blue and with the help of Pct540 ${ }_{C p}$, the E. coli mutant also allows converting glucose into $4 \mathrm{HB}-\mathrm{CoA}$ in vivo (Choi et al. 2016, 2020a). In addition, the deletion of the succinate semialdehyde dehydrogenase genes (sad and $g a b D$ ) can increase 4HB monomer fraction in the copolymers (Li et al. 2017). In another study, deleting the $y n e I$ and $g a b D$ genes, which coding succinate semialdehyde dehydrogenase too, can also increase $4 \mathrm{HB}$ monomer fraction in the copolymers (Choi et al. 2016, 2020a).

\section{Introduction of glycolate (GL) biosynthesis pathway}

In 2011, the copolymers containing GL were synthesized in E. coli LS5218 for the first time with exogenous GL (Matsumoto et al. 2011). Subsequently, the methods for providing endogenous GL by modulating the metabolic pathway were established gradually. Establishing the Dahms pathway $\left(\mathrm{XylBC}_{c c s}\right)$ in E. coli XL1-Blue by introducing of the xylose dehydrogenase gene $(x y l B)$ and the xylonolactonase gene $(x y l C)$ of Caulobacter crescentus allows converting xylose into GL in vivo (Choi et al. 2016, 2017, 2020a). The native glyoxylate bypass pathway of $E$. coli is amplified by the overexpression of the isocitrate lyase gene (aceA), the isocitrate dehydrogenase kinase/phosphatase gene $(a c e K)$, and the glyoxylate reductase gene $(y c d W)$, which allows converting glucose into GL in vivo. 


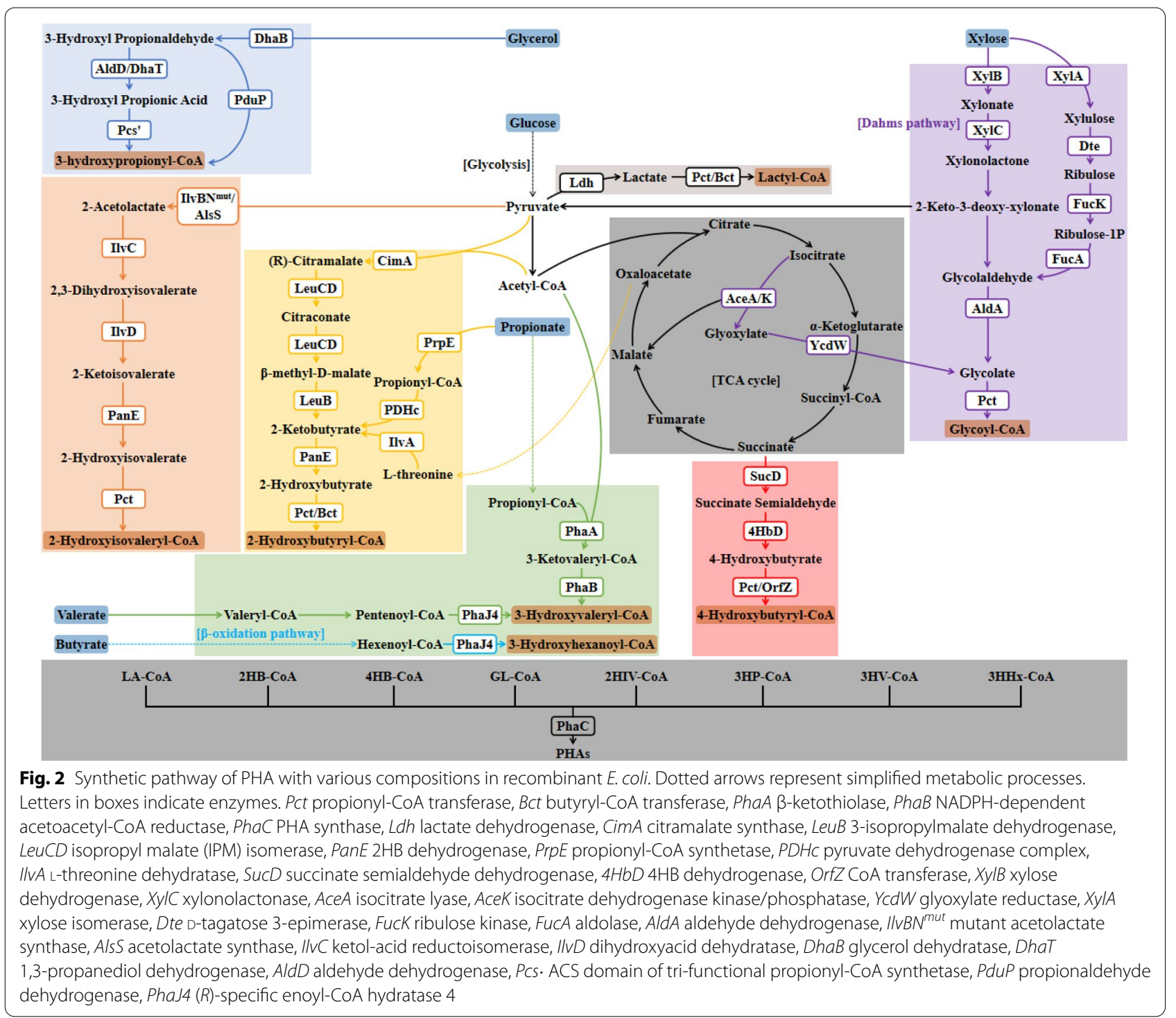

The deletion of the glycolate oxidase gene $(\mathrm{glcD})$ can increase GL monomer fraction in the copolymers ( $\mathrm{Li}$ et al. 2016, 2017). The introduction of the D-tagatose 3-epimerase gene (dte) of Pseudomonas cichorii and the overexpression of the native genes [the ribulose kinase gene $(f u c K)$, the aldolase gene $(f u c A)$, and the aldehyde dehydrogenase gene (aldA)] in E. coli K12 also allow converting xylose into GL in vivo (Da et al. 2019).

\section{Introduction of other 2-hydroxyalkanoates (2HA) biosynthesis pathway}

The introduction of the mutant acetolactate synthase gene $\left(i l v B N^{m u t}\right)$ [or the $B$. subtilis acetolactate synthase gene $(a l s S)]$, the ketol-acid reductoisomerase gene $(i l v C)$, and the dihydroxyacid dehydratase gene $(i l v D)$ of $E$. coli W3110 into E. coli XL1-Blue allows converting glucose into 2-hydroxyisovalerate (2HIV) with the help of the panE gene in vivo. In addition, adding L-valine into the medium can also increase 2HIV monomer fraction in the copolymers (Choi et al. 2016; Yang et al. 2016). The introduction of the $l d h A$ and hadA genes into E. coli DH5a allows converting glucose/xylose/glycerol into $2 \mathrm{HA}-\mathrm{CoA}$ (2HP, 2H3MB, 2H3MV, 2H4MV, and 2H3PhP) with the supplement of different amino acids in vivo (Mizuno et al. 2018). 
Introduction of 3-hydroxypropionate (3HP) biosynthesis pathway

The introduction of the glycerol dehydratase gene (dhaB) of Klebsiella pneumoniae, the 1,3-propanediol dehydrogenase gene (dhaT) and the aldehyde dehydrogenase gene (aldD) of P. putida KT2442, as well as the ACS domain of tri-functional propionyl-CoA synthetase gene $\left(p c s^{\prime}\right)$ of Chloroflexus aurantiacus into E. coli S17-1 allows converting glycerol into 3HP-CoA in vivo (Ren et al. 2017). The introduction of the glycerol dehydratase gene (dhaB123) of K. pneumoniae and the propionaldehyde dehydrogenase gene ( $p d u P)$ of Salmonella typhimurium LT2 into E. coli JM109 also allows converting glycerol into 3HP-CoA in vivo (Zhao et al. 2018).

\section{Introduction of $3 \mathrm{HV}$ and medium-chain-length 3-hydroxyalkanoates (3HA) biosynthesis pathway} Using E. coli BW25113 along with the pflA gene deletion, $3 \mathrm{HV}$-CoA can be supplied from propionate, which is esterified into propionyl-CoA by proposed inherent pathways (such as acetyl-CoA synthetase and propionylCoA synthetase) firstly. Then, Propionyl-CoA is converted into 3HV-CoA by PhaAB (Shozui et al. 2010b). The introduction of the $(R)$-specific enoyl-CoA hydratase 4 gene (phaJ4) of $P$. aeruginosa into E. coli LS5218 allows converting valerate into $3 \mathrm{HV}-\mathrm{CoA}$ in vivo with the help of the $\beta$-oxidation pathway (Shozui et al. 2011). In addition, with the same strategies (using the phaJ4 gene and the $\beta$-oxidation pathway together), E. coli LS5218 can polymerize $3 \mathrm{HHx}$ into the copolymers from butyrate (Shozui et al. 2010a) and polymerize 3HA (3HB, 3HHx, $3 \mathrm{HO}, 3 \mathrm{HD}$, and $3 \mathrm{HDD}$ ) into the copolymers from dodecanoate (Matsumoto et al. 2011). Moreover, the introduction of enzymes for the synthesis of 3HA monomers with medium-chain length into the $f a d R$ gene deleted $E$. coli allows converting glucose into $3 \mathrm{HA}(3 \mathrm{HB}, 3 \mathrm{HO}, 3 \mathrm{HD}$, 3HDD, and 3H5DD) in vivo (Goto et al. 2019a).

\section{Microorganisms other than E. coli for $\mathrm{P}(\mathrm{LA}-\mathrm{CO}-3 \mathrm{HB})$ biosynthesis}

Due to the relatively mature metabolic regulation mechanism and molecular tools, $E$. coli is the most widely used chassis cell in the copolymer production. While in recent years, some other non-traditional chassis cells also have been developed and applied.

As an endotoxin-free platform, a Gram-positive bacteria Corynebacterium glutamicum is metabolic engineered to produce the copolymers. After introducing LPE and monomer supplying enzymes, $2.4 \mathrm{wt} \% \mathrm{P}(96.8 \mathrm{~mol} \%$ LA-co-3HB) is synthesized by engineered strain in a medium with $60 \mathrm{~g} / \mathrm{L}$ glucose. LA monomer fraction is further increased to $99.3 \mathrm{~mol} \%$ after the phaAB gene deletion, while the copolymer content is decreased to $1.4 \mathrm{wt} \%$ (Song et al. 2012).

Cupriavidus necator is one of the most effective platforms for producing various PHAs. With the expression of LPE and monomer supplying enzymes, $C$. necator 437-540 can synthesize $33.9 \mathrm{wt} \% \mathrm{P}(37 \mathrm{~mol} \% \mathrm{LA}-\mathrm{co}-3 \mathrm{HB})$ in a medium containing $20 \mathrm{~g} / \mathrm{L}$ glucose. Furthermore, $2 \mathrm{HB}$ and $3 \mathrm{HV}$ can be polymerized into the copolymers by this strain when $2 \mathrm{HB}$ is added to the medium (Park et al. 2013b). Introducing the $s a c C$ and $l d h A$ genes into C. necator $437-540$ can synthesize $19.5 \mathrm{wt} \% \mathrm{P}(21.5 \mathrm{~mol} \%$ LA-co-3HB) in a medium with $20 \mathrm{~g} / \mathrm{L}$ sucrose (Park et al. 2015).

Considering the higher production efficiency and the lower cost of the copolymers, Sinorhizobium meliloti is selected as a production platform. Pct532 $C p$ and PhaC1400 ${ }_{P S 6-19}$ are introduced into S. meliloti Rm1021 and the native PHA synthase enzyme gene $(p h b C)$ is replaced. Under the control of the native $p h b C$ promoter, engineered strain can synthesize $\mathrm{P}(30 \mathrm{~mol} \% \mathrm{LA}-\mathrm{co}-3 \mathrm{HB})$ in a medium containing mannitol. This is the first report of the copolymer production in Alphaproteobacteria (Tran and Charles 2016).

\section{Conclusions}

Due to the rising price of crude oil, the depletion of petroleum resources, and the environmental damage caused by plastic wastes, PLA and its copolymers have become the potential substitutes for the degradable synthetic plastics and the "green copolymers" made from renewable resources. Therefore, they have attracted more and more attention in the fields of industry, medicine, and research. The researches of the lactate-based copolymers, which possess broad application prospects, not only greatly improve the properties of PLA, but also greatly expand the application field of it.

It has become a trend to utilize inexpensive extraneous carbon sources (such as glucose and glycerol) and/ or mixed cultures (such as agricultural wastes) in the production. Recombinant E. coli has been developed as a conventional platform to produce the copolymers (Choi et al. 2020b). The strategies of the copolymer production are generally to overcome the shortcomings of inducible promoters and/or introduce new key enzymes. Because of the ability of $E$. coli to use a variety of cheap and unrelated carbon sources, the large-scale bioreactors production from the culture in shake flasks should be further studied to obtain a more efficient fermentation process. In addition, the separation and the purification of the copolymers from $E$. coli is also one of the research directions.

With the further development of the potential recombinant $E$. coli strains and other related strains, it is not 
only helpful to expand the production types of the copolymers but also can improve the productivity and the yield of the copolymers, making copolymer recycling more convenient and economical. In order to replace the plastics derived from the petrochemical industry ideally, more researches should be conducted on reducing the production costs and improving the properties of bioplastics.

\begin{abstract}
Abbreviations
PLA: Polylactic acid; LA: Lactate; P(LA-co-3HB): Poly(lactate-co-3-hydroxybutyrate); PHA: Polyhydroxyalkanoate; Ldh: Lactate dehydrogenase; Pct: Propionyl-CoA transferase; PhaA: $\beta$-Ketothiolase; PhaB: NADPH-dependent acetoacetyl-CoA reductase; PhaC: PHA synthase; 3HB: 3-Hydroxybutyrate; P(3HB): Poly(3-hydroxybutyrate); 3HV: 3-Hydroxyvalerate; 4HB: 4-Hydroxybutyrate; LPE: LA-CoA polymerizing enzyme; $2 \mathrm{HB}$ : 2-Hydroxybutyrate; Bct: Butyryl-CoA transferase; FldA: Cinnamoyl-CoA:phenyllactate CoA-transferase; HadA: Isocaprenoyl-CoA:2-hydroxyisocaproate CoA-transferase; GatC: Non-ATP consuming galactitol permease; PflB: Pyruvate formate lyase; PflA: Pyruvate formate lyase activating enzyme; Mlc: Multiple regulator of glucose and xylose uptake; LDE: LA-CoA degrading enzyme; DOC: Dissolved oxygen concentration; CimA: Citramalate synthase; LeuB: 3-Isopropylmalate dehydrogenase; LeuCD: Isopropyl malate isomerase; IPM: Isopropyl malate; PanE: $2 \mathrm{HB}$ dehydrogenase; PrpE: Propionyl-CoA synthetase; PDHc: Pyruvate dehydrogenase complex; IlvA: L-Threonine dehydratase; SucD: Succinate semialdehyde dehydrogenase; 4HbD: 4-Hydroxybutyrate dehydrogenase; OrfZ: CoA transferase; XylB: Xylose dehydrogenase; XylC: Xylonolactonase; AceA: Isocitrate lyase; AceK: Isocitrate dehydrogenase kinase/phosphatase; YcdW: Glyoxylate reductase; $\mathrm{Xy|A}$ : Xylose isomerase; Dte: D-Tagatose 3-epimerase; FucK: Ribulose kinase; FucA: Aldolase; AldA: Aldehyde dehydrogenase; IlvBN ${ }^{\text {mut: }}$ Mutant acetolactate synthase; AlsS: Acetolactate synthase; IlvC: Ketol-acid reductoisomerase; IlvD: Dihydroxyacid dehydratase; DhaB: Glycerol dehydratase; DhaT: 1,3-Propanediol dehydrogenase; AldD: Aldehyde dehydrogenase; PCs': ACS domain of trifunctional propionyl-CoA synthetase; PduP: Propionaldehyde dehydrogenase; PhaJ4: (R)-Specific enoyl-CoA hydratase 4; GL: Glycolate; 2HA: 2-Hydroxyalkanoate; $2 \mathrm{HIV}$ : 2-Hydroxyisovalerate; $2 \mathrm{HP}$ : 2-Hydroxypropionate; $2 \mathrm{H} 3 \mathrm{MB}$ : 2-Hydroxy-3-methylbutyrate; $2 \mathrm{H} 3 \mathrm{MV}$ : 2-Hydroxy-3-methylvalerate; $2 \mathrm{H} 4 \mathrm{MV}$ : 2-Hydroxy-4-methylvalerate; $2 \mathrm{H} 3 \mathrm{PhP}: 2$-Hydroxy-3-phenylpropionate; $3 \mathrm{HP}$ : 3-Hydroxypropionate; 3HA: 3-Hydroxyalkanoate; $3 \mathrm{HHx}$ : 3-Hydroxyhexanoate; 3HO: 3-Hydroxyoctanoate; 3HD: 3-Hydroxydecanoate; 3HDD: 3-Hydroxydodecanoate; 3H5DD: 3-Hydroxy-5-cis-dodecenoate.
\end{abstract}

\section{Acknowledgements}

The National Natural Science Foundation of China (Grant No. 21776083), the National Key Research and Development Program of China (Grant No. 2017YFB0309302), the Science and Technology Commission of Shanghai Municipality (Grant No. 21DZ1209100), the Fundamental Research Funds for the Central Universities (Grant No. 22221818014), the 111 Project (B18022).

\section{Authors' contributions}

$P G, Y L$ and $H W$ conceived and designed the review. PG, YL and HW wrote the paper. JW revised the paper. HW supervised the paper and has funding acquisition. All authors read and approved the final manuscript.

\section{Funding}

This study was funded by the National Natural Science Foundation of China (Grant No. 21776083), the National Key Research and Development Program of China (Grant No. 2017YFB0309302), the Science and Technology Commission of Shanghai Municipality (Grant No. 21DZ1209100), the Fundamental Research Funds for the Central Universities (Grant No. 22221818014), the 111 Project (B18022).

\section{Availability of data and materials}

Not applicable.

\section{Declarations}

Ethics approval and consent to participate

All authors read and approved the final manuscript and related ethics.

\section{Consent for publication}

All authors read and approved the final manuscript and potential publication.

\section{Competing interests}

The authors declare that they have no competing interests.

\section{Author details}

${ }^{1}$ State Key Laboratory of Bioreactor Engineering, School of Biotechnology, East China University of Science and Technology, 130 Meilong Road, Shanghai 200237, China. ${ }^{2}$ Shanghai Collaborative Innovation Center for Biomanufacturing Technology, 130 Meilong Road, Shanghai 200237, China. ${ }^{3}$ Key Laboratory of Bio-Based Material Engineering of China National Light Industry Council, 130 Meilong Road, Shanghai 200237, China.

Received: 8 August 2021 Accepted: 12 October 2021

Published online: 22 October 2021

\section{References}

Chae CG, Kim YJ, Lee SJ, Oh YH, Yang JE, Joo JC, Kang KH, Jang Y-A, Lee H, Park AR, Song BK, Lee SY, Park SJ (2016) Biosynthesis of poly(2hydroxybutyrate-co-lactate) in metabolically engineered Escherichia coli. Biotechnol Bioprocess Eng 21(1):169-174. https://doi.org/10.1007/ s12257-015-0749-x

Choi SY, Park SJ, Kim WJ, Yang JE, Lee H, Shin J, Lee SY (2016) One-step fermentative production of poly(lactate-co-glycolate) from carbohydrates in Escherichia coli. Nat Biotechnol 34(4):435-440. https://doi.org/10.1038/ nbt.3485

Choi SY, Kim WJ, Yu SJ, Park SJ, Im SG, Lee SY (2017) Engineering the xylose-catabolizing Dahms pathway for production of poly(D-lactate-co-glycolate) and poly(D-lactate-co-glycolate-co-D-2-hydroxybutyrate) in Escherichia coli. Microb Biotechnol 10(6):1353-1364. https://doi.org/10.1111/17517915.12721

Choi SY, Chae TU, Shin J, Im JA, Lee SY (2020a) Biosynthesis and characterization of poly(D-lactate-co-glycolate-co-4-hydroxybutyrate). Biotechnol. Bioeng 117(7):2187-2197. https://doi.org/10.1002/bit.27354

Choi SY, Rhie MN, Kim HT, Joo JC, Cho IJ, Son J, Jo SY, Sohn YJ, Baritugo KA, Pyo J, Lee Y, Lee SY, Park SJ (2020b) Metabolic engineering for the synthesis of polyesters: a 100-year journey from polyhydroxyalkanoates to non-natural microbial polyesters. Metab Eng 58:47-81. https://doi.org/10.1016/j. ymben.2019.05.009

Clomburg JM, Vick JE, Blankschien MD, Rodriguez-Moya M, Gonzalez R (2012) A synthetic biology approach to engineer a functional reversal of the B-oxidation cycle. ACS Synth Biol 1(11):541-554. https://doi.org/10.1021/ sb3000782

Da Y, Li W, Shi L, Li Z (2019) Microbial production of poly (glycolate-co-lactate-co-3-hydroxybutyrate) from glucose and xylose by Escherichia coli. Chin J Biotechnol 35(2):254-262. https://doi.org/10.13345/j.cjb.180199

David Y, Joo JC, Yang JE, Oh YH, Lee SY, Park SJ (2017) Biosynthesis of 2-hydroxyacid-containing polyhydroxyalkanoates by employing butyrylCoA transferases in metabolically engineered Escherichia coli. Biotechnol J 12(11):1700116. https://doi.org/10.1002/biot.201700116

Giammona G, Craparo EF (2018) Biomedical applications of polylactide (PLA) and its copolymers. Molecules. https://doi.org/10.3390/molecules230409 80

Goto S, Hokamura A, Shiratsuchi H, Taguchi S, Matsumoto K, Abe H, Tanaka K, Matsusaki H (2019a) Biosynthesis of novel lactate-based polymers containing medium-chain-length 3-hydroxyalkanoates by recombinant Escherichia coli strains from glucose. J Biosci Bioeng 128(2):191-197. https://doi.org/10.1016/j.jbiosc.2019.01.009

Goto S, Suzuki N, Matsumoto K, Taguchi S, Tanaka K, Matsusaki H (2019b) Enhancement of lactate fraction in poly(lactate-co-3-hydroxybutyrate) 
synthesized by Escherichia coli harboring the D-lactate dehydrogenase gene from Lactobacillus acetotolerans HT. J Gen Appl Microbiol 65(4):204208. https://doi.org/10.2323/jgam.2018.09.002

Haile A, Gelebo GG, Tesfaye T, Mengie W, Mebrate MA, Abuhay A, Limeneh DY (2021) Pulp and paper mill wastes: utilizations and prospects for high value-added biomaterials. Bioresour Bioprocess 8(1):1-22. https://doi.org/ 10.1186/s40643-021-00385-3

Han X, Satoh Y, Satoh T, Matsumoto K, Kakuchi T, Taguchi S, Dairi T, Munekata M, Tajima K (2011) Chemo-enzymatic synthesis of polyhydroxyalkanoate (PHA) incorporating 2-hydroxybutyrate by wild-type class I PHA synthase from Ralstonia eutropha. Appl Microbiol Biotechnol 92(3):509-517. https://doi.org/10.1007/s00253-011-3362-8

Hori C, Yamazaki T, Ribordy G, Takisawa K, Matsumoto K, Ooi T, Zinn M, Taguchi S (2019) High-cell density culture of poly(lactate-co-3-hydroxybutyrate)producing Escherichia coli by using glucose/xylose-switching fed-batch jar fermentation. J Biosci Bioeng 127(6):721-725. https://doi.org/10. 1016/j.jbiosc.2018.11.006

Ishii D, Takisawa K, Matsumoto K, Ooi T, Hikima T, Takata M, Taguchi S, Iwata $T$ (2017) Effect of monomeric composition on the thermal, mechanical and crystalline properties of poly[(R)-lactate-co-(R)-3-hydroxybutyrate]. Polymer 122:169-173. https://doi.org/10.1016/j.polymer.2017.06.039

Jiang Z, Zhang J (2013) Lipase-catalyzed synthesis of aliphatic polyesters via copolymerization of lactide with diesters and diols. Polymer 54(22):61056113. https://doi.org/10.1016/j.polymer.2013.09.005

Jung YK, Lee SY (2011) Efficient production of polylactic acid and its copolymers by metabolically engineered Escherichia coli. J Biotechnol 151(1):94-101. https://doi.org/10.1016/j.jbiotec.2010.11.009

Jung YK, Kim TY, Park SJ, Lee SY (2010) Metabolic engineering of Escherichia coli for the production of polylactic acid and its copolymers. Biotechnol Bioeng 105(1):161-171. https://doi.org/10.1002/bit.22548

Kadoya R, Matsumoto K, Ooi T, Taguchi S (2015a) MtgA deletion-triggered cell enlargement of Escherichia coli for enhanced intracellular polyester accumulation. PLoS ONE 10(6):e0125163. https://doi.org/10.1371/journal. pone. 0125163

Kadoya R, Kodama Y, Matsumoto K, Taguchi S (2015b) Enhanced cellular content and lactate fraction of the poly(lactate-co-3-hydroxybutyrate) polyester produced in recombinant Escherichia coli by the deletion of sigma factor RpoN. J Biosci Bioeng 119(4):427-429. https://doi.org/10 1016/j.jbiosc.2014.09.001

Kadoya R, Kodama Y, Matsumoto K, Ooi T, Taguchi S (2017) Genome-wide screening of transcription factor deletion targets in Escherichia coli for enhanced production of lactate-based polyesters. J Biosci Bioeng 123(5):535-539. https://doi.org/10.1016/j.jbiosc.2016.12.018

Kadoya R, Matsumoto K, Takisawa K, Ooi T, Taguchi S (2018) Enhanced production of lactate-based polyesters in Escherichia coli from a mixture of glucose and xylose by Mlc-mediated catabolite derepression. J Biosci Bioeng 125(4):365-370. https://doi.org/10.1016/j.jbiosc.2017.11.003

Kim YJ, Chae CG, Kang KH, Oh YH, Joo JC, Song BK, Lee SY, Park SJ (2016) Biosynthesis of lactate-containing polyhydroxyalkanoates in Recombinant Escherichia coli by employing new CoA transferases. KSBB J 31 (1):27-32. https://doi.org/10.7841/ksbbj.2016.31.1.27

Langsdorf A, Volkmar M, Holtmann D, Ulber R (2021) Material utilization of green waste: a review on potential valorization methods. Bioresour Bioprocess 8(1):1-26. https://doi.org/10.1186/s40643-021-00367-5

Lee Y, Cho IJ, Choi SY, Lee SY (2019) Systems metabolic engineering strategies for non-natural microbial polyester production. Biotechnol J 14(9):e1800426. https://doi.org/10.1002/biot.201800426

Li ZJ, Qiao K, Shi W, Pereira B, Zhang H, Olsen BD, Stephanopoulos G (2016) Biosynthesis of poly (glycolate-co-lactate-co-3-hydroxybutyrate) from glucose by metabolically engineered Escherichia coli. Metab Eng 35:1-8. https://doi.org/10.1016/j.ymben.2016.01.004

Li ZJ, Qiao K, Che XM, Stephanopoulos G (2017) Metabolic engineering of Escherichia coli for the synthesis of the quadripolymer poly(glycolate-colactate-co-3-hydroxybutyrate-co-4-hydroxybutyrate) from glucose. Metab Eng 44:38-44. https://doi.org/10.1016/j.ymben.2017.09.003

Lu J, Li Z, Ye Q, Wu H (2019) Effect of reducing the activity of respiratory chain on biosynthesis of poly(3-hydroxybutyrate-co-lactate) in Escherichia coli. Chin J Biotechnol 35(1):59-69. https://doi.org/10.13345/j.cjb.180107

Makadia HK, Siegel SJ (2011) Poly lactic-co-glycolic acid (PLGA) as biodegradable controlled drug delivery carrier. Polymers 3(3):1377-1397. https:// doi.org/10.3390/polym3031377
Matsumoto K, Taguchi S (2010) Enzymatic and whole-cell synthesis of lactatecontaining polyesters: toward the complete biological production of polylactate. Appl Microbiol Biotechnol 85(4):921-932. https://doi.org/10. 1007/s00253-009-2374-0

Matsumoto K, Taguchi S (2013a) Biosynthetic polyesters consisting of 2-hydroxyalkanoic acids: current challenges and unresolved questions. Appl Microbiol Biotechnol 97(18):8011-8021. https://doi.org/10.1007/ s00253-013-5120-6

Matsumoto K, Taguchi S (2013b) Enzyme and metabolic engineering for the production of novel biopolymers: crossover of biological and chemical processes. Curr Opin Biotechnol 24(6):1054-1060. https://doi.org/10. 1016/j.copbio.2013.02.021

Matsumoto K, Ishiyama A, Sakai K, Shiba T, Taguchi S (2011) Biosynthesis of glycolate-based polyesters containing medium-chain-length 3-hydroxyalkanoates in recombinant Escherichia coli expressing engineered polyhydroxyalkanoate synthase. J Biotechnol 156(3):214-217. https://doi.org/10. 1016/j.jbiotec.2011.07.040

Matsumoto K, Terai S, Ishiyama A, Sun J, Kabe T, Song Y, Nduko JM, Iwata T, Taguchi S (2013) One-pot microbial production, mechanical properties, and enzymatic degradation of isotactic $\mathrm{P}[(R)-2$-hydroxybutyrate $]$ and its copolymer with (R)-lactate. Biomacromolecules 14(6):1913-1918. https:// doi.org/10.1021/bm400278j

Matsumoto K, lijima M, Hori C, Utsunomia C, Ooi T, Taguchi S (2018) In vitro analysis of D-lactyl-CoA-polymerizing polyhydroxyalkanoate synthase in polylactate and poly(lactate-co-3-hydroxybutyrate) syntheses. Biomacromolecules 19(7):2889-2895. https://doi.org/10.1021/acs.biomac.8b00454

Mizuno S, Enda Y, Saika A, Hiroe A, Tsuge T (2018) Biosynthesis of polyhydroxyalkanoates containing 2-hydroxy-4-methylvalerate and 2-hydroxy3-phenylpropionate units from a related or unrelated carbon source. J Biosci Bioeng 125(3):295-300. https://doi.org/10.1016/j.jbiosc.2017.10.010

Nduko JM, Taguchi S (2019) Microbial production and properties of LA-based polymers and oligomers from renewable feedstock. In: Fang Z, Smith JRL, Tian X-F (eds) Production of materials from sustainable biomass resources. Springer, Singapore, pp 361-390. https://doi.org/10.1007/978981-13-3768-0_12

Nduko JM, Matsumoto K, Ooi T, Taguchi S (2013) Effectiveness of xylose utilization for high yield production of lactate-enriched P(lactate-co-3-hydroxybutyrate) using a lactate-overproducing strain of Escherichia coli and an evolved lactate-polymerizing enzyme. Metab Eng 15:159-166. https:// doi.org/10.1016/j.ymben.2012.11.007

Nduko JM, Matsumoto K, Ooi T, Taguchi S (2014) Enhanced production of poly(lactate-co-3-hydroxybutyrate) from xylose in engineered Escherichia coli overexpressing a galactitol transporter. Appl Microbiol Biotechnol 98(6):2453-2460. https://doi.org/10.1007/s00253-013-5401-0

Ochi A, Matsumoto K, Ooba T, Sakai K, Tsuge T, Taguchi S (2013) Engineering of class I lactate-polymerizing polyhydroxyalkanoate synthases from Ralstonia eutropha that synthesize lactate-based polyester with a block nature. Appl Microbiol Biotechnol 97(8):3441-3447. https://doi.org/10. 1007/s00253-012-4231-9

Oh YH, Kang K-H, Shin J, Song BK, Lee SH, Lee SY, Park SJ (2014) Biosynthesis of lactate-containing polyhydroxyalkanoates in recombinant Escherichia coli from sucrose. KSBB J 29(6):443-447. https://doi.org/10.7841/ksbbj.2014. 29.6.443

Oh YH, Lee SH, Jang YA, Choi JW, Hong KS, Yu JH, Shin J, Song BK, Mastan SG, David Y, Baylon MG, Lee SY, Park SJ (2015) Development of rice bran treatment process and its use for the synthesis of polyhydroxyalkanoates from rice bran hydrolysate solution. Bioresour Technol 181:283-290. https:// doi.org/10.1016/j.biortech.2015.01.075

Pang X, Zhuang X, Tang Z, Chen X (2010) Polylactic acid (PLA): research, development and industrialization. Biotechnol J 5(11):1125-1136. https://doi. org/10.1002/biot.201000135

Park SJ, Lee SY, Kim TW, Jung YK, Yang TH (2012a) Biosynthesis of lactatecontaining polyesters by metabolically engineered bacteria. Biotechnol J 7(2):199-212. https://doi.org/10.1002/biot.201100070

Park SJ, Lee TW, Lim SC, Kim TW, Lee H, Kim MK, Lee SH, Song BK, Lee SY (2012b) Biosynthesis of polyhydroxyalkanoates containing 2-hydroxybutyrate from unrelated carbon source by metabolically engineered Escherichia coli. Appl Microbiol Biotechnol 93(1):273-283. https://doi.org/ 10.1007/s00253-011-3530-x

Park SJ, Kang KH, Lee H, Park AR, Yang JE, Oh YH, Song BK, Jegal J, Lee SH, Lee SY (2013a) Propionyl-CoA dependent biosynthesis of 2-hydroxybutyrate 
containing polyhydroxyalkanoates in metabolically engineered Escherichia coli. J Biotechnol 165(2):93-98. https://doi.org/10.1016/j.jbiotec.2013. 03.005

Park SJ, Jang YA, Lee H, Park AR, Yang JE, Shin J, Oh YH, Song BK, Jegal J, Lee SH, Lee SY (2013b) Metabolic engineering of Ralstonia eutropha for the biosynthesis of 2-hydroxyacid-containing polyhydroxyalkanoates. Metab Eng 20:20-28. https://doi.org/10.1016/j.ymben.2013.08.002

Park SJ, Jang YA, Noh W, Oh YH, Lee H, David Y, Baylon MG, Shin J, Yang JE, Choi SY, Lee SH, Lee SY (2015) Metabolic engineering of Ralstonia eutropha for the production of polyhydroxyalkanoates from sucrose. Biotechnol Bioeng 112(3):638-643. https://doi.org/10.1002/bit.25469

Plácido J, Capareda S (2016) Conversion of residues and by-products from the biodiesel industry into value-added products. Bioresour Bioprocess 3(1):1-12. https://doi.org/10.1186/s40643-016-0100-1

Ren Y, Meng D, Wu L, Chen J, Wu Q, Chen GQ (2017) Microbial synthesis of a novel terpolyester $\mathrm{P}(\mathrm{LA}-\mathrm{co}-3 \mathrm{HB}-\mathrm{co}-3 \mathrm{HP})$ from low-cost substrates. Microb Biotechnol 10(2):371-380. https://doi.org/10.1111/1751-7915.12453

Salamanca-Cardona L, Scheel RA, Lundgren BR, Stipanovic AJ, Matsumoto K, Taguchi S, Nomura CT (2014a) Deletion of the pflA gene in Escherichia coli LS5218 and its effects on the production of polyhydroxyalkanoates using beechwood xylan as a feedstock. Bioengineered 5(5):284-287. https:// doi.org/10.4161/bioe.29595

Salamanca-Cardona L, Ashe CS, Stipanovic AJ, Nomura CT (2014b) Enhanced production of polyhydroxyalkanoates (PHAs) from beechwood xylan by recombinant Escherichia coli. Appl Microbiol Biotechnol 98(2):831-842. https://doi.org/10.1007/s00253-013-5398-4

Salamanca-Cardona L, Scheel RA, Mizuno K, Bergey NS, Stipanovic AJ, Matsumoto K, Taguchi S, Nomura CT (2017) Effect of acetate as a co-feedstock on the production of poly(lactate-co-3-hydroxyalkanoate) by pflA-deficient Escherichia coli RSC10. J Biosci Bioeng 123(5):547-554. https://doi. org/10.1016/j.jbiosc.2016.12.019

Shah AA, Kato S, Shintani N, Kamini NR, Nakajima-Kambe T (2014) Microbial degradation of aliphatic and aliphatic-aromatic co-polyesters. Appl Microbiol Biotechnol 98(8):3437-3447. https://doi.org/10.1007/ s00253-014-5558-1

Shozui F, Matsumoto K, Sasaki T, Taguchi S (2009) Engineering of polyhydroxyalkanoate synthase by Ser477X/Gln481X saturation mutagenesis for efficient production of 3-hydroxybutyrate-based copolyesters. Appl Microbiol Biotechnol 84(6):1117-1124. https://doi.org/10.1007/ s00253-009-2052-2

Shozui F, Matsumoto K, Motohashi R, Yamada M, Taguchi S (2010a) Establishment of a metabolic pathway to introduce the 3-hydroxyhexanoate unit into LA-based polyesters via a reverse reaction of $\beta$-oxidation in Escherichia coli LS5218. Polym Degrad Stab 95(8):1340-1344. https://doi.org/10. 1016/j.polymdegradstab.2010.01.029

Shozui F, Matsumoto K, Nakai T, Yamada M, Taguchi S (2010b) Biosynthesis of novel terpolymers poly(lactate-co-3-hydroxybutyrate-co-3-hydroxyvalerate)s in lactate-overproducing mutant Escherichia coli JW0885 by feeding propionate as a precursor of 3-hydroxyvalerate. Appl Microbiol Biotechnol 85(4):949-954. https://doi.org/10.1007/s00253-009-2100-y

Shozui F, Matsumoto K, Motohashi R, Sun J, Satoh T, Kakuchi T, Taguchi S (2011) Biosynthesis of a lactate (LA)-based polyester with a 96mol\% LA fraction and its application to stereocomplex formation. Polym Degrad Stab 96(4):499-504. https://doi.org/10.1016/j.polymdegradstab.2011.01.007

Singh AK, Srivastava JK, Chandel AK, Sharma L, Mallick N, Singh SP (2019) Biomedical applications of microbially engineered polyhydroxyalkanoates: an insight into recent advances, bottlenecks, and solutions. Appl Microbiol Biotechnol 103(5):2007-2032. https://doi.org/10.1007/ s00253-018-09604-y

Singhvi MS, Zinjarde SS, Gokhale DV (2019) Polylactic acid: synthesis and biomedical applications. J Appl Microbiol 127(6):1612-1626. https://doi. org/10.1111/jam. 14290

Södergård A, Stolt M (2002) Properties of lactic acid based polymers and their correlation with composition. Prog Polym Sci 27(6):1123-1163. https:// doi.org/10.1016/50079-6700(02)00012-6

Sohn YJ, Kim HT, Baritugo KA, Song HM, Ryu MH, Kang KH, Jo SY, Kim H, Kim YJ, Choi Jl, Park SK, Joo JC, Park SJ (2020) Biosynthesis of polyhydroxyalkanoates from sucrose by metabolically engineered Escherichia coli strains. Int J Biol Macromol 149:593-599. https://doi.org/10.1016/j.ijbio mac.2020.01.254
Song Y, Matsumoto K, Yamada M, Gohda A, Brigham CJ, Sinskey AJ, Taguchi S (2012) Engineered Corynebacterium glutamicum as an endotoxin-free platform strain for lactate-based polyester production. Appl Microbiol Biotechnol 93(5):1917-1925. https://doi.org/10.1007/s00253-011-3718-0

Su M, Xie J, Zeng Q, Shu M, Liu J, Jiang Z (2020) Enzymatic synthesis of PEGylated lactide-diester-diol copolyesters for highly efficient targeted anticancer drug delivery. Mater Sci Eng C Mater Biol Appl 115:111125. https://doi.org/10.1016/j.msec.2020.111125

Sudo M, Hori C, Ooi T, Mizuno S, Tsuge T, Matsumoto K (2020) Synergy of valine and threonine supplementation on poly(2-hydroxybutyrate-block3-hydroxybutyrate) synthesis in engineered Escherichia coli expressing chimeric polyhydroxyalkanoate synthase. J Biosci Bioeng 129(3):302-306. https://doi.org/10.1016/j.jbiosc.2019.09.018

Sun J, Utsunomia C, Sasaki S, Matsumoto K, Yamada T, Ooi T, Taguchi S (2016) Microbial production of poly(lactate-co-3-hydroxybutyrate) from hybrid Miscanthus-derived sugars. Biosci Biotechnol Biochem 80(4):818-820. https://doi.org/10.1080/09168451.2015.1116933

Taguchi S, Doi Y (2004) Evolution of polyhydroxyalkanoate (PHA) production system by "enzyme evolution": successful case studies of directed evolution. Macromol Biosci 4(3):146-156. https://doi.org/10.1002/mabi.20030 0111

Taguchi S, Matsumoto K (2020) Evolution of polyhydroxyalkanoate synthesizing systems toward a sustainable plastic industry. Polym J 53(1):67-79. https://doi.org/10.1038/s41428-020-00420-8

Taguchi S, Yamada M, Matsumoto K, Tajima K, Satoh Y, Munekata M, Ohno K, Kohda K, Shimamura T, Kambe H, Obata S (2008) A microbial factory for lactate-based polyesters using a lactate-polymerizing enzyme. Proc Natl Acad Sci USA 105(45):17323-17327. https://doi.org/10.1073/pnas.08056 53105

Tajima K, Satoh Y, Satoh T, Itoh R, Han X, Taguchi S, Kakuchi T, Munekata M (2009) Chemo-enzymatic synthesis of poly(lactate-co-(3-hydroxybutyrate)) by a lactate-polymerizing enzyme. Macromolecules 42(6):19851989. https://doi.org/10.1021/ma802579g

Takisawa K, Ooi T, Matsumoto K, Kadoya R, Taguchi S (2017) Xylose-based hydrolysate from eucalyptus extract as feedstock for poly(lactate-co3-hydroxybutyrate) production in engineered Escherichia coli. Process Biochem 54:102-105. https://doi.org/10.1016/j.procbio.2016.12.019

Tran TT, Charles TC (2016) Genome-engineered Sinorhizobium meliloti for the production of poly(lactic-co-3-hydroxybutyric) acid copolymer. Can J Microbiol 62(2):130-138. https://doi.org/10.1139/cjm-2015-0255

Wei X, Wu J, Guo P, Zhou S, Wu H (2021) Effect of short-chain thioesterase deficiency on P(3HB-co-LA) biosynthesis in Escherichia coli. Chin J Biotechnol 37(1):196-206. https://doi.org/10.13345/j.cjb.200243

Wu J, Wei X, Guo P, He A, Xu J, Jin M, Zhang Y, Wu H (2021) Efficient poly(3hydroxybutyrate-co-lactate) production from corn stover hydrolysate by metabolically engineered Escherichia coli. Bioresour Technol. https://doi. org/10.1016/j.biortech.2021.125873

Yadav M, Goswami P, Paritosh K, Kumar M, Pareek N, Vivekanand V (2019) Seafood waste: a source for preparation of commercially employable chitin/chitosan materials. Bioresour Bioprocess 6(1):1-20. https://doi.org/ 10.1186/s40643-019-0243-y

Yamada M, Matsumoto K, Nakai T, Taguchi S (2009) Microbial production of lactate-enriched poly[(R)-lactate-co-(R)-3-hydroxybutyrate] with novel thermal properties. Biomacromolecules 10(4):677-681. https://doi.org/10. $1021 / \mathrm{bm} 8013846$

Yamada M, Matsumoto K, Shimizu K, Uramoto S, Nakai T, Shozui F, Taguchi S (2010) Adjustable mutations in lactate (LA)-polymerizing enzyme for the microbial production of LA-based polyesters with tailor-made monomer composition. Biomacromolecules 11(3):815-819. https://doi.org/10.1021/ bm901437z

Yamada M, Matsumoto K, Uramoto S, Motohashi R, Abe H, Taguchi S (2011) Lactate fraction dependent mechanical properties of semitransparent poly(lactate-co-3-hydroxybutyrate)s produced by control of lactyl-CoA monomer fluxes in recombinant Escherichia coli. J Biotechnol 154(4):255260. https://doi.org/10.1016/j.jbiotec.2011.05.011

Yang TH, Kim TW, Kang HO, Lee SH, Lee EJ, Lim SC, Oh SO, Song AJ, Park SJ, Lee SY (2010) Biosynthesis of polylactic acid and its copolymers using evolved propionate CoA transferase and PHA synthase. Biotechnol Bioeng 105(1):150-160. https://doi.org/10.1002/bit.22547

Yang TH, Jung YK, Kang HO, Kim TW, Park SJ, Lee SY (2011) Tailor-made type II Pseudomonas PHA synthases and their use for the biosynthesis 
of polylactic acid and its copolymer in recombinant Escherichia coli. Appl Microbiol Biotechnol 90(2):603-614. https://doi.org/10.1007/ s00253-010-3077-2

Yang JE, Choi SY, Shin JH, Park SJ, Lee SY (2013) Microbial production of lactate-containing polyesters. Microb Biotechnol 6(6):621-636. https:// doi.org/10.1111/1751-7915.12066

Yang JE, Kim JW, Oh YH, Choi SY, Lee H, Park AR, Shin J, Park SJ, Lee SY (2016) Biosynthesis of poly(2-hydroxyisovalerate-co-lactate) by metabolically engineered Escherichia coli. Biotechnol J 11(12):1572-1585. https://doi. org/10.1002/biot.201600420

Yang JE, Park SJ, Kim WJ, Kim HJ, Kim BJ, Lee H, Shin J, Lee SY (2018) Onestep fermentative production of aromatic polyesters from glucose by metabolically engineered Escherichia coli strains. Nat Commun 9(1):79. https://doi.org/10.1038/s41467-017-02498-w

Zhao Z, Stephen LT, Xian M, Liu X, Feng X, Zhao G (2018) Biosynthesis of poly (3-hydroxypropionate-co-lactate) from glycerol by engineered Escherichia coli. China Biotechnol 38(2):46-53. https://doi.org/10.13523/j.cb.20180 207

Zikmanis P, Kolesovs S, Semjonovs P (2020) Production of biodegradable microbial polymers from whey. Bioresour Bioprocess 7(1):1-15. https:// doi.org/10.1186/s40643-020-00326-6

\section{Publisher's Note}

Springer Nature remains neutral with regard to jurisdictional claims in published maps and institutional affiliations.

\section{Submit your manuscript to a SpringerOpen ${ }^{\circ}$ journal and benefit from:}

- Convenient online submission

- Rigorous peer review

- Open access: articles freely available online

- High visibility within the field

- Retaining the copyright to your article

Submit your next manuscript at $\gg$ springeropen.com 